\title{
Effect of Germinated Maize and Sorghum Based Diets on Carcass Parameters and Economics Production of Kadaknath
}

\author{
Mehdi Ali Khan ${ }^{1}$, Archana Jain ${ }^{1}$, J. Shakkarpude ${ }^{2}$, M.K. Mehta ${ }^{3}$, \\ Shweta Singh Chauhan ${ }^{*}$ and D.D. Caesar ${ }^{2}$ \\ ${ }^{1}$ Department of Veterinary Physiology, College of Veterinary Science \& A.H.., NDVSU, \\ Mhow, M.P., India \\ ${ }^{2}$ Department of Veterinary Physiology, College of Veterinary Science \& A.H., NDVSU, \\ Jabalpur, M.P., India \\ ${ }^{3}$ Department of Animal Nutrition, College of Veterinary Science \& A.H., NDVSU, \\ Mhow, M.P., India \\ ${ }^{4}$ Department of Veterinary Biochemistry, College of Veterinary Science \& A.H., NDVSU, \\ Jabalpur, M.P., India \\ *Corresponding author
}

\begin{abstract}
A B S T R A C T
Poultry is a domesticated species of birds reared for production of eggs, meat, feather, etc. Kadaknath is an important indigenous breed of poultry inhabitation in vast areas of Western Madhya Pradesh mainly the Jhabua and Dhar districts and adjoining areas of

\begin{tabular}{|l|}
\hline Ke y w or d s \\
Germination, \\
Sorghum, Maize, \\
Kadaknath, Carcass, \\
Economics production \\
\hline Article Info \\
\hline Accepted: \\
12 July 2018 \\
Available Online: \\
10 August 2018 \\
\hline \hline
\end{tabular}
Gujarat and Rajasthan. Kadaknath breed most of the internal organs exhibit intense black colouration which is due to the deposition of melanin pigment in the connective tissue of organs and in the dermis. The nutritive value of maize and sorghum seed depends on the technological processes used, such as milling, oil extraction, starch separation and germination. The present experiment was conducted on 240 day old Kadaknath chicks belonging to same hatch and randomly divided into six treatment groups of 40 chicks each viz., GM0, GM1, GM2, GS0, GS1 and GS2. Control groups (GM0) and (GS0) were given standard ration with $100 \%$ normal maize and $100 \%$ normal sorghum based diet respectively. The treatment Group GM1 and GM2 was given diet containing standard ration with $50 \%$ germinated maize and $75 \%$ germinated maize respectively. Group GS1 and GS2 were given diet containing standard ration with 50\% germinated sorghum and $75 \%$ germinated sorghum respectively. Supplementation of maize at $75 \%$ level is more economical than germinated sorghum in the feed. It is more economical and profitable to the farmers as there was no addition of costly feed additives in the ration of Kadaknath birds.
\end{abstract}

\section{Introduction}

Poultry keeping is practiced by majority of the poor and marginalized rural households all over India. These households rely on low cost backyard poultry rearing to supplement and enhance their livelihoods. It not only provides nutritional security but also reduces the 
livelihood vulnerability, and promotes gender equality. Kadaknath is an important indigenous breed of poultry inhabiting vast areas of Western Madhya Pradesh mainly the Jhabua and Dhar districts and adjoining areas of Gujarat and Rajasthan. Though the flesh of this breed is black, it is considered not only a delicacy of distinctive taste, but also of medicinal value.

Sorghum is the fifth most important crop after wheat, rice, corn, and barley (Bryden et al., 2009). Maize is one of the main cereals used in feeding broiler chickens worldwide. It is free of viscous non-starch polysaccharides, the major anti-nutritive factor present in most other cereals like barley, wheat, and oats. At present the feed industry is using maize as a basic energy source in poultry diets. The total calorific value and nutritional composition of maize and sorghum are similar. Nutritional value of germinated grain improves due to the conversion of complex compounds into simpler and assimiable form and by minimizing the effect of anti-nutritional factors during germination (Chavan and Kadam, 1989). Sprouting of grains can be used advantageously as it has resulted not only in increase protein quantity but quality also.

\section{Materials and Methods}

The present experiment was conducted on 240 day old Kadaknath chicks belonging to same hatch and randomly divided into six treatment groups of 40 chicks each viz., GM0, GM1, GM2, GS0, GS1 and GS2. Each group was further divided into four replications of 10 birds each. The duration of the experiment was carried out for 90 days. Control groups (GM0) and (GS0) were given standard ration with $100 \%$ normal maize and $100 \%$ normal sorghum based diet respectively. The treatment Group GM1 was given diet containing standard ration with 50\% germinated maize. The Group GM2 was given diet containing standard ration with $75 \%$ germinated maize. Group GS1 was given diet containing standard ration with 50\% germinated sorghum. Group GS2 was given diet containing standard ration with $75 \%$ germinated sorghum. The experimental birds were vaccinated against Ranikhet disease and Gumboro disease/IBD at appropriate time.

The birds were housed in deep litter system in the well ventillated and lighted rooms and the feed was given ad.lib. with plenty of fresh water. The body weights of day old chicks were recorded on arrival and thereafter on weekly intervals. Blood was collected on every $30^{\text {th }}$ days from each bird. About $3-4 \mathrm{ml}$ was collected from wing vein using 22-24 gauge needle in a clean dry vial containing 2.0 $\mathrm{mg} / \mathrm{ml}$ Ethylene diamine tetra acetic acid, Sodium salt (EDTA) as an anticoagulant for haematological analysis. All observations were analyzed by using ANOVA to compare different treatment group.

\section{Results and Discussion}

\section{Carcass Traits}

\section{Edible carcass yield (g)}

The mean values of edible carcass yield for GM0, GM1, GM2, GS0, GS1 and GS2, were $301.00 \pm 2.64, \quad 309.09 \pm 3.53, \quad 384.00 \pm 2.27$, $212.50 \pm 2.10,371.50 \pm 1.32$ and $284.25 \pm 2.17$, respectively and the edible carcass yield was significantly $(\mathrm{p}<0.01)$ increased in all treatments groups as compared to control group (Table 1).

\section{Breast yield (g)}

The mean values of breast yield for GM0, GM1, GM2, GS0, GS1 and GS2, were $145.75 \pm 2.28, \quad 151.25 \pm 1.79, \quad 160.00 \pm 2.19$, $126.50 \pm 1.70,153.75 \pm 2.01$ and $139.25 \pm 1.75$, respectively and breast yield was significantly 
$(\mathrm{p}<0.01)$ increased in all treatments group (Table 1).

\section{Thigh yield (g)}

The mean values of thigh yield for GM0, GM1, GM2, GS0, GS1 and GS2, were $69.00 \pm 0.91, \quad 79.50 \pm 1.04, \quad 93.50 \pm 1.70$, $59.75 \pm 1.37, \quad 83.00 \pm 1.47$ and $63.50 \pm 1.93$, respectively and thigh yield was significantly $(\mathrm{p}<0.01)$ increased in all treatment group (Table 1).

\section{Intestinal length $(\mathrm{cm})$}

The mean values of intestinal length for GM0, GM1, GM2, GS0, GS1 and GS2, were $128.01 \pm 0.40, \quad 122.52 \pm 0.65, \quad 120.26 \pm 0.47$, $121.29 \pm 0.47,118.88 \pm 0.46$ and $119.28 \pm 0.47$, respectively. The length of intestine was significantly $(\mathrm{P}<0.01)$ decreased in all treated groups (Table 1).

\section{Meat weight (g)}

The mean values of Meat weight for GM0, GM1, GM2, GS0, GS1 and GS2, were $36.75 \pm 0.75, \quad 42.25 \pm 0.85, \quad 44.00 \pm 1.82$, $29.50 \pm 1.19, \quad 41.25 \pm 1.25$ and $38.50 \pm 1.19$, respectively.

The result revealed that the meat weight (thigh muscles) was significantly $(\mathrm{P}<0.01)$ increased in all treated groups as compared to control group (Table 1).

\section{Weight of intestine (g)}

The mean values of intestinal weight for GM0, GM1, GM2, GS0, GS1 and GS2, were $67.50 \pm 0.28, \quad 62.75 \pm 0.85, \quad 61.25 \pm 0.47$, $63.00 \pm 1.08, \quad 59.25 \pm 0.47$ and $60.18 \pm 0.12$, respectively, and The weight of intestine (small + large intestine) was significantly $(\mathrm{P}<0.01)$ decreased in all treatment groups (Table 1).

\section{Bone weight (g)}

The mean values of bone weight for GM0, GM1, GM2, GS0, GS1 and GS2, were $15.75 \pm 0.85, \quad 16.75 \pm 0.85, \quad 16.00 \pm 0.91$, $14.50 \pm 0.64, \quad 15.75 \pm 1.18$ and $16.00 \pm 1.08$, respectively. The bone weight (femur bone) was significantly $(\mathrm{P}<0.05)$ increased in all treated groups as compared to control (Table $1)$.

\section{Meat bone ratio}

The mean values of meat bone ratio for GM0, GM1, GM2, GS0, GS1 and GS2, were 2.35, $2.52,2.75,2.03,2.61$ and 2.40 , respectively. The meat bone ratio was highly significantly $(\mathrm{P}<0.01)$ different, in all treated group as compared to control group (Table 1).

\section{Economics of Kadaknath production}

Total expenditure and total selling price per bird in 90 days for groups GM0, GM1, GM2, GS0, GS1, and GS2, were Rs. 126.90, 125.82, 122.07, 131.47, 124.38 and 126.49 and Rs 238.54, 278.84, 312.69, 241.01, 280.45 and 262.39, respectively. Total profit per bird for groups GM0, GM1, GM2, GS0, GS1, and GS2 were Rs. 111.64, 153.02, 190.62, 109.54, 156.07 and 135.90 (Table 2).

The present study revealed that the edible carcass yield, thigh and breast meat weights, bone weight and meat: bone ratio were significantly $(\mathrm{P}<0.01)$ increased in all treated groups as compared to control. This may be due to germinated sorghum and maize which may increase the enzyme activity causing better feed utilization in the gastrointestinal tract and released minerals for growth (Rajpoot, 2009). The results of the present study were in accordance with the values reported by Jain (2008), Prajapati (2010), Hana et al., (2010), Melingasuk et al., (2012), Jamre (2015), and Gautam (2015). 
Table.1 Effect of germinated maize and sorghum on carcass parameters in Kadaknath (Mean \pm SE)

\begin{tabular}{|c|c|c|c|c|c|c|c|c|}
\hline Parameters & $\begin{array}{c}\text { GM0 } \\
(\text { control) }\end{array}$ & GM1 & GM2 & & $\begin{array}{c}\text { GS0 } \\
(\text { control })\end{array}$ & GS1 & GS2 & \\
\hline Edible carcass & $301.00^{\mathrm{a}}$ & $309.09^{\mathrm{a}}$ & $384.00^{\mathrm{b}}$ & $* *$ & $212.50^{\mathrm{a}}$ & $371.50^{\mathrm{b}}$ & $284.25^{\mathrm{c}}$ & $* *$ \\
yield $(\mathrm{g})$ & \pm 2.64 & \pm 3.53 & \pm 2.27 & & \pm 2.10 & \pm 1.32 & \pm 2.17 & \\
\hline Breast yield & $145.75^{\mathrm{a}}$ & $151.25^{\mathrm{a}}$ & $160.00^{\mathrm{b}}$ & $* *$ & $126.50^{\mathrm{a}}$ & $153.75^{\mathrm{b}}$ & $139.25^{\mathrm{c}}$ & $* *$ \\
$(\mathrm{~g})$ & \pm 2.28 & \pm 1.79 & \pm 2.19 & & \pm 1.70 & \pm 2.01 & \pm 1.75 & \\
\hline Thigh yield & $69.00^{\mathrm{a}}$ & $79.50^{\mathrm{b}}$ & $93.50^{\mathrm{c}}$ & $* *$ & $59.75^{\mathrm{a}}$ & $83.00^{\mathrm{b}}$ & $63.50^{\mathrm{a}}$ & $* *$ \\
\hline (g) & \pm 0.91 & \pm 1.04 & \pm 1.70 & & \pm 1.37 & \pm 1.47 & \pm 1.93 & \\
\hline Intestinal & $128.01^{\mathrm{a}}$ & $122.52^{\mathrm{b}}$ & $120.26^{\mathrm{b}}$ & $* *$ & $121.29^{\mathrm{a}}$ & $118.88^{\mathrm{b}}$ & $119.28^{\mathrm{c}}$ & $*$ \\
\hline Length $(\mathrm{cm})$ & \pm 040 & \pm 0.65 & \pm 0.47 & & \pm 0.47 & \pm 0.46 & \pm 0.47 & \\
\hline Meat weight & $36.75^{\mathrm{a}}$ & $42.25^{\mathrm{ab}}$ & $44.00^{\mathrm{b}}$ & $* *$ & $29.50^{\mathrm{a}}$ & $41.25^{\mathrm{b}}$ & $38.50^{\mathrm{c}}$ & $* *$ \\
\hline (g) & \pm 0.75 & \pm 0.85 & \pm 1.82 & & \pm 1.19 & \pm 1.25 & \pm 1.19 & \\
\hline Weight of & $67.50^{\mathrm{a}}$ & $62.75^{\mathrm{b}}$ & $61.25^{\mathrm{a}}$ & $* *$ & $63.00^{\mathrm{a}}$ & $59.25^{\mathrm{b}}$ & $60.18^{\mathrm{b}}$ & $*$ \\
\hline intestine $(\mathrm{g})$ & \pm 0.28 & \pm 0.85 & \pm 0.47 & & \pm 1.08 & \pm 0.47 & \pm 0.12 & \\
\hline Bone weight & $15.75^{\mathrm{a}}$ & $16.75^{\mathrm{b}}$ & $16.00^{\mathrm{a}}$ & $*$ & $14.50^{\mathrm{a}}$ & $15.75^{\mathrm{b}}$ & $16.00^{\mathrm{b}}$ & $*$ \\
\hline (g) & \pm 0.85 & \pm 0.85 & \pm 0.91 & & \pm 0.64 & \pm 1.18 & \pm 1.08 & \\
\hline Meat Bone & $2.35^{\mathrm{a}}$ & $2.52^{\mathrm{b}}$ & $2.75^{\mathrm{c}}$ & $* *$ & $2.03^{\mathrm{a}}$ & $2.61^{\mathrm{c}}$ & $2.40^{\mathrm{b}}$ & $* *$ \\
\hline Ratio & \pm 0.23 & \pm 0.22 & \pm 0.31 & & \pm 0.02 & \pm 0.28 & \pm 0.26 & \\
\hline
\end{tabular}

**Shows Significance at $1 \%$ level as compared to control group $(\mathrm{P}<0.01)$

*Shows Significance at 5\% level as compared to control group $(\mathrm{P}<0.05)$

The value with the different superscripts in a row are different significantly between groups The value with the no superscripts in a row are having no significant relationship

Table.2 Effect of germinated maize and sorghum on Economics of Kadaknath production

\begin{tabular}{|c|c|c|c|c|c|c|c|}
\hline $\begin{array}{l}\text { S. } \\
\text { No. }\end{array}$ & COST & GM0 & GM1 & GM2 & GS0 & GS1 & GS2 \\
\hline 1. & Total feed cost / bird (Rs) & 69.90 & 65.82 & 62.07 & 74.47 & 64.38 & 66.49 \\
\hline 2. & Chicks cost /bird (Rs) & 40.00 & 40.00 & 40.00 & 40.00 & 40.00 & 40.00 \\
\hline 3. & $\begin{array}{c}\text { Electricity cost /bird } \\
(R s)\end{array}$ & 5.00 & 5.00 & 5.00 & 5.00 & 5.00 & 5.00 \\
\hline 4. & $\begin{array}{c}\text { Vaccines and Medicines } \\
\text { /bird (Rs) }\end{array}$ & 5.00 & 5.00 & 5.00 & 5.00 & 5.00 & 5.00 \\
\hline 5. & $\begin{array}{c}\text { Management cost /bird } \\
(R s)\end{array}$ & 7.00 & 10.00 & 10.00 & 7.00 & 10.00 & 10.00 \\
\hline 6. & $\begin{array}{l}\text { Total expenditure /bird } \\
(\text { Rs) }\end{array}$ & 126.90 & 125.82 & 122.07 & 131.47 & 124.38 & 126.49 \\
\hline 7. & $\begin{array}{l}\text { Total selling price /bird } \\
\text { (Rs) }\end{array}$ & 238.54 & 278.84 & 312.69 & 241.01 & 280.45 & 262.39 \\
\hline 8. & Profit/ bird (Rs) & 111.64 & 153.02 & 190.62 & 109.54 & 156.07 & 135.90 \\
\hline
\end{tabular}


The length of intestine and weight of intestine significantly decreased in all the treated groups as compared to control in both germinated maize and sorghum supplemented groups. On the other hand, Namra et al., (2011) reported non-significant difference in intestinal length and weight after treatment. There was no significant change in all carcass parameters between maize and sorghum supplemented groups.

Supplementation of maize at $75 \%$ level is more economical than germinated sorghum in the feed. It is more economical and profitable to the farmers as there was no addition of costly feed additives in the ration of Kadaknath birds.

\section{Acknowledgement}

Authors are thankful to the Dean, College of Vety. Sci. and Animal Husbandry, Jabalpur, for providing necessary facilities to carry out this research.

\section{Statement of Ethical rights}

Authors declare that prior to the start of experiment all necessary ethical permissions were taken from Institute Animal Ethics Committee, College of Veterinary Science \& A.H., Jabalpur.

\section{Conflict of Interest}

Declared as none.

\section{References}

Bryden, W.L., P. H. Selle, D.J. Cadogan, X. Li, N.D. Muller and Jordan, D.R. 2009. A Review of The Nutritive Value of Sorghum in Broilers. Rural Industries Research and Development Corporation
(RIRDC) Publication No 09/077, Canberra, Australia.

Chavan, J., and Kadam, S. S. 1989. Nutritional Improvement of Cereals by Sprouting. Critical Reviews in Food Science and Nutrition. 28(5): 401-437.

Gautam, M., 2015. Comparative Studies on Growth and Production Performance of Broilers on Diets Containing Germinated Sorghum and Multienzyme Complex. M.V.Sc \& A.H. Thesis (Veterinary Physiology), Nanaji Deshmukh Veterinary Science University, Jabalpur (M.P).

Hana, A.H., A.R. Zakaria Mohammad, Jalal and Majdi, A. A. 2010. The Influence of Supplemental Multi-Enzyme Feed Additive on the Performance, Carcass Characteristics and Meat Quality Traits of Broiler Chickens. International Journal of Poultry Science. 9(2): 126133.

Jain, A., 2008. Biochemical and Haematological Parameters in Broilers. Indian Journal Animal Nutrition. 25(3): 285-287.

Jamre, B., 2015. Evalution of Diet Containing Germinated Maize and Multienzyme Complex on Growth and Production Performance of Broilers. M.V.Sc \& A.H. Thesis. (Veterinary Physiology), Nanaji Deshmukh Veterinary Science University, Jabalpur (M.P).

Melingasuk, M., S. Gibril and Ahmed, A. E. E. 2012. Effect of Sorghum Tannin on the Performance of Broiler Chicks and Their Carcass Characteristics. University of Khartum. Juba. Agriculture. Science. 20 (3): 329-346.

Mourya, S., 2015. Effects of Various Energy and Protein Levels on Performance of Kadaknath Birds. M.V.Sc \& A.H. Thesis (Animal Nutrition), Nanaji Deshmukh Veterinary Science University, Jabalpur (M.P). 2015. 


\section{How to cite this article:}

Mehdi Ali Khan, Archana Jain, J. Shakkarpude, M.K. Mehta, Shweta Singh Chauhan and Caesar, D.D. 2018. Effect of Germinated Maize and Sorghum Based Diets on Carcass Parameters and Economics Production of Kadaknath. Int.J.Curr.Microbiol.App.Sci. 7(08): 2385-2390. doi: https://doi.org/10.20546/ijcmas.2018.708.240 